\title{
Current ankle sprain prevention and management strategies of netball athletes: a scoping review of the literature and comparison with best-practice recommendations
}

\author{
Patrick L. Rowe ${ }^{0}$, Adam L. Bryant and Kade L. Paterson*
}

\begin{abstract}
Background: Ankle sprains are the most commonly reported injury in netball. Approximately four in five netball athletes will sustain an ankle sprain, up to half will go on to sustain recurrent ankle sprains, and nine in ten report perceived ankle instability. Historically, prevention and management strategies of ankle sprains and injuries have been investigated for a variety of sports, however, no literature reviews have investigated these in netball athletes, or compared these with current best-practice within the literature. Therefore, this scoping review aims to understand how netball athletes currently prevent and manage ankle sprains and to compare these approaches with best-practice recommendations.
\end{abstract}

Methods: A literature search was conducted using MEDLINE, CINAHL, and SPORTDiscus databases using keywords to capture studies with data or information related to the prevention and management of ankle sprains and injuries in netball.

Results: The search strategy captured 982 studies across all databases, with 30 netball studies included in this scoping review. Studies suggest netball athletes are not commonly referred to health professionals, do not undertake adequate rehabilitation, and almost immediately return to court following an ankle sprain or injury. Current bestpractices suggest injury prevention programs and external ankle support effectively reduce ankle sprains and injuries; however, poor compliance and implementation may be a significant barrier. Currently, there is a lack of evidence that netball-specific footwear reduces the risk of ankle sprains.

Conclusion: The findings suggest netball athletes do not implement current best-practice prevention and management strategies following an ankle sprain. This is despite evidence of the effectiveness of injury prevention programs, external ankle support, and adequate rehabilitation in reducing ankle sprain rates. Current-best practice prevention and management of ankle sprains should be considered by clinicians, coaches, and athletes to reduce the prevalence and chronicity of ankle sprains in netball.

\footnotetext{
*Correspondence: kade.paterson@unimelb.edu.au

Department of Physiotherapy, Centre for Health, Exercise and Sports

Medicine, School of Health Sciences, Faculty of Medicine, Dentistry and Health Sciences, The University of Melbourne, Melbourne, VIC,

Australia
}

(c) The Author(s) 2021. Open Access This article is licensed under a Creative Commons Attribution 4.0 International License, which permits use, sharing, adaptation, distribution and reproduction in any medium or format, as long as you give appropriate credit to the original author(s) and the source, provide a link to the Creative Commons licence, and indicate if changes were made. The images or other third party material in this article are included in the article's Creative Commons licence, unless indicated otherwise in a credit line to the material. If material is not included in the article's Creative Commons licence and your intended use is not permitted by statutory regulation or exceeds the permitted use, you will need to obtain permission directly from the copyright holder. To view a copy of this licence, visit http://creativecommons.org/licenses/by/4.0/. The Creative Commons Public Domain Dedication waiver (http://creativeco mmons.org/publicdomain/zero/1.0/) applies to the data made available in this article, unless otherwise stated in a credit line to the data. 
Keywords: Netball, Ankle sprains, Ankle injuries, Chronic ankle instability, External ankle support, Prevention, Management, Rehabilitation, Return to sport

\section{Background}

Netball is one of the leading female sporting codes worldwide with over 20 million participants across 80 countries [1, 2]. It is an intermittent, high-intensity sport played within a limited court space where athletes undertake repeated cutting, pivoting, jumping, landing, and sprint efforts $[3,4]$. The fast-paced, frenetic nature of netball, in conjunction with the one-step rule, is considered key factor for injury risk during match-play $[5,6]$. Ankle sprains are the most commonly reported injury, accounting for approximately $40 \%$ of all netball injuries $[7,8]$. In fact, netball has one of the highest incidence rates of ankle sprains in worldwide sport [7]. Ankle sprains during netball typically result from poor landing mechanics or player contact, resulting in an inversion-internal rotation mechanism [9].

One study has shown up to four in five netball athletes will have sustained at least one ankle sprain in their lifetime [10]. Unfortunately, many netball athletes sustain their index ankle sprain from a very young age, with a recent study reporting an $84 \%$ increase in the number of ankle sprains in the 10-14 year age group over 10 years [11]. Currently, there is considerable concern a large proportion of netball athletes who sustain an ankle sprain will go on to develop chronic ankle instability (CAI). CAI is characterised by recurrent ankle sprains and/or feelings or perception the ankle joint is 'unstable', and/or self-reported disability, for at least one year following an index ankle sprain $[12,13]$. Up to half of all netball, athletes will also go on to sustain recurrent ankle sprains, more commonly bilateral recurrent sprains, following an index sprain [10, 14]. Furthermore, nine in ten netball athletes with a history of ankle sprains report some form of ankle instability, with $64 \%$ demonstrating moderate-severe instability [10].

Historically, netball injuries have been well documented since the nineteen-eighties. However, there has only been one broad review investigating injury prevention and management in netball [15]. The review did not specifically focus on ankle sprains and was published more than two decades ago. Since this time, there have been a plethora of studies have investigated injury prevention and management strategies in netball over the previous decade, in particular ankle sprains, suggesting an updated review of the literature is required [16]. To our knowledge, no study has investigated the current management and prevention strategies undertaken by netball athletes following an ankle sprain or injury, nor compared these findings with best-practice guidelines available from the literature. This scoping review aims to (1) understand how netball athletes currently prevent and manage ankle sprains or injuries, (2) compare the current practices of netball athletes with bestpractice guidelines for prevention and management of ankle sprains or injuries, and (3) consider what prevention and management strategies for ankle sprains can be improved or better implemented when undertaken by netball athletes.

\section{Methods \\ Search strategy}

Due to the broad nature of the topic, a scoping review was chosen as the appropriate method of presenting the data and evidence. The preferred reporting items for systematic review and meta-analyses extension for scoping reviews (PRISMA-ScR) were adopted and are presented in Additional file 1 (PRISMA ScR checklist) [17]. A literature search was conducted using MEDLINE, CINAHL, and SPORTDiscus databases on July 15th, 2021. The search included a combination of free-text terms including "netball" AND "ankle" OR "sprain" OR "injur" OR "instability" OR "CAI" OR "epidemiolog" OR "incidence" OR "prevalence" OR "data" OR "statistic" OR "pattern"” OR "rehab" OR "treat" " OR "manage*" OR "prevent" OR "brac" OR "tap"” OR "ankle support" OR "footwear" OR "shoe" OR "warm-up" OR "program". Database searches and captured studies are presented in Additional file 2 (search strategy).

\section{Study inclusion}

Studies were eligible if they (1) were published in a peerreviewed journal; (2) randomised, cross-sectional and observational studies explicitly investigated a netball cohort; (3) included data or information related to ankle sprains and injuries (ankle fractures, contusions, and deltoid ligament sprains); and (4) investigated prevention and management related to ankle sprains and injuries. Studies were excluded if they did not provide data or information related to ankle sprains and/or injuries or did not include a netball cohort. Non-English language studies, review articles, conference proceedings, or abstracts which did not provide sufficient data were also excluded. The reference list and citations of captured studies were cross-referenced to identify additional studies relevant to this review. 


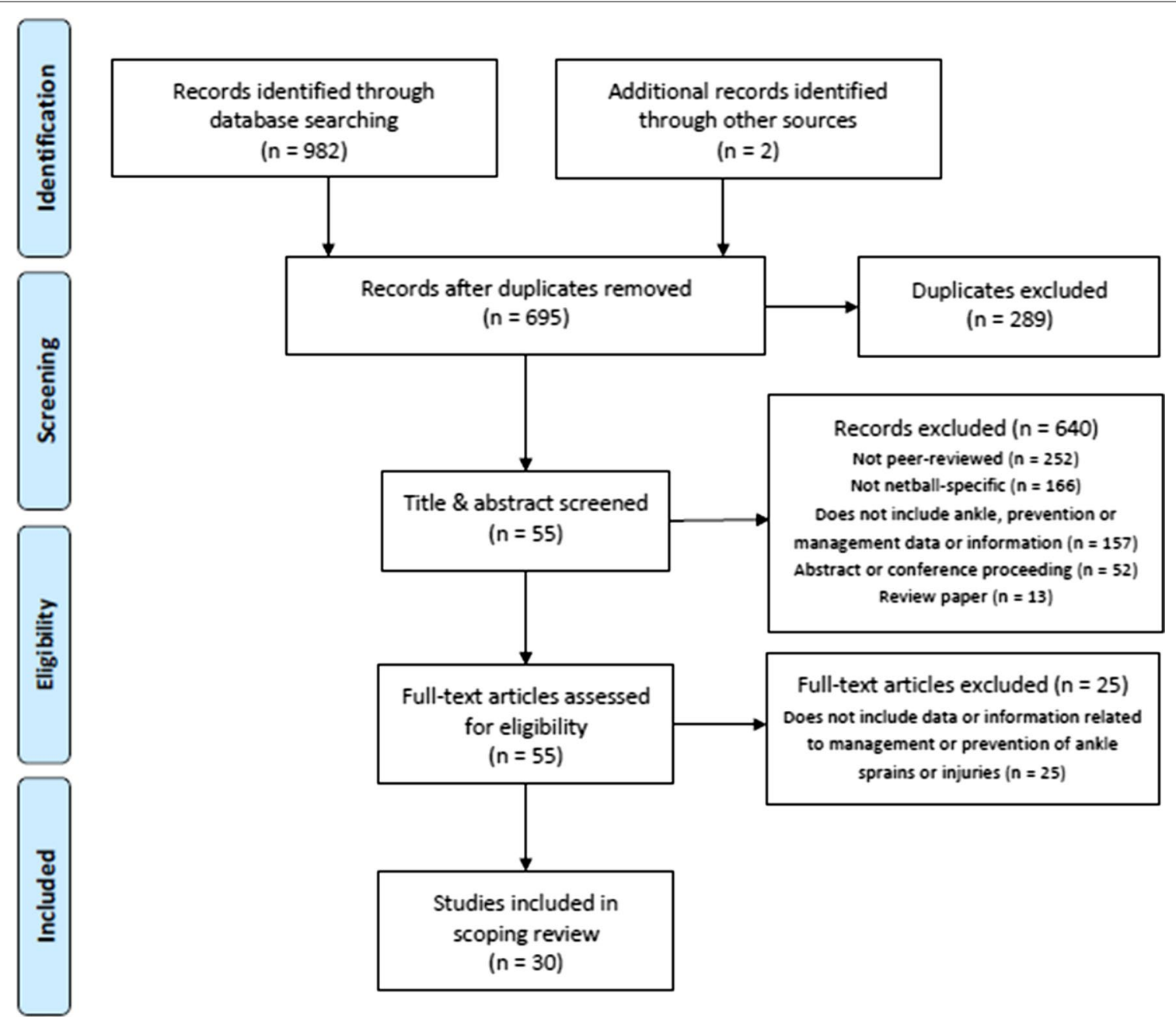

Fig. 1 PRISMA flowchart

\section{Data extraction and analysis}

Two authors (PLR and KLP) reviewed and collected data from the included studies. Author, year of publication, study design, sample size, age of participants and key findings relevant to this review were all extracted and collated. Authors of the relevant studies were contacted if data was unavailable. Following data collation, literature trends were identified and classified into sub-categories within prevention and management, and described in as a narrative synthesis. Participant data was presented as number, mean and standard deviations if available, while study outcomes were presented as proportions, ranges and $\mathrm{p}$ values as appropriate.

\section{Results and discussion Study identification}

The search strategy captured 982 studies across all databases. Two additional studies were identified by cross-referencing and reference lists. Once duplicates were removed, 695 studies remained. Fifty-five studies remained following a review of title and abstract. Upon full-text review, thirty studies were included in this scoping review [10, 18-46]. Figure 1 provides an overview of the search strategy and study inclusion using the PRISMA flowchart.

\section{Prevention of ankle sprains in netball}

Twenty-five studies presented data related to the prevention of ankle sprains and injuries in netball. Three subcategories were identified; these include injury prevention programs (14 studies), external ankle support (11 studies), and footwear (5 studies).

\section{Injury prevention program}

In South Africa, more than half of all injured elite netball athletes reportedly did not undertake core stability, proprioceptive, or neuromuscular and landing training [27]. One study found that a six-week gluteal strengthening, 
core stability, and proprioceptive program improved dynamic balance in university netball athletes [33]. In 2013, Netball New Zealand introduced a dynamic warmup and education program titled NetballSmart [29]. Two years later, Netball Australia implemented a nationwide injury prevention program titled Knee Injury Prevention for Netballers to Enhance Performance and Extend Play (KNEE) aiming to reduce lower limb injuries, in particular knee and ankle injuries [26]. The NetballSmart program has been shown to reduce peak vGRF and improve landing mechanics in junior netball athletes [34]. But to this date, no study has investigated the effectiveness of the NetballSmart and KNEE programs on ankle injury rates in netball.

Currently, the greatest challenge of injury prevention programs in netball is poor implementation rates $[41,42]$. Only $12-18 \%$ of the recommended activities from the Netball KNEE program were undertaken by communitylevel junior netball athletes [40]. Concerningly, strength, balance, and agility-specific exercises were rarely performed [40]. Evidence suggests that trunk and lower limb strengthening and proprioceptive exercises significantly reduce injury rates, particularly ankle injuries, whilst also improving sprint, agility, and jumping performance [35, $37,39]$. Poor implementation of injury prevention programs at the community level may limit its influence on netball injuries [40]. Barriers include athlete and coach engagement, education, resources, and time [41, 42]. Education sessions for netball coaches resulted in greater knowledge and implementation of injury prevention programs [36]. The authors recommended the inclusion of coach education sessions and accessible resources to improve implementation rates [36]. Optimistically, more than four in five netball coaches strongly support the use of injury prevention programs and report competency in teaching a safe landing program to junior netball athletes [44]. Furthermore, most netball athletes report positive beliefs and attitudes towards undertaking a safe landing program [45].

\section{External ankle support}

External ankle support is a common injury prevention measure undertaken by netball athletes. One study found $34.4 \%$ of state netball athletes wore external ankle support during a tournament [23]. Another study found approximately half of netball athletes reported using taping $(30.8 \%)$ or bracing (18.8\%) [24]. However, the same study found $68.2 \%$ were not wearing external ankle support when they sustained an ankle injury [24]. Attenborough et al. [10] found $70 \%$ of club and inter-district netball athletes with CAI regularly use external ankle support, suggesting the implementation of external ankle support dramatically increases once an ankle sprain is sustained. Interestingly, one study reported a three-fold increase in lower limb injury risk for netball athletes who wore external ankle support but did not provide data specifically on ankle sprains [46].

Several studies reported significant reductions in sagittal or frontal plane biomechanics with external ankle support during landing and cutting tasks [25, 30, 31]. Furthermore, significant reductions in gastrocnemius and peroneus longus electromyography (EMG) activity were also shown with the addition of external ankle support during landing tasks [28]. With external ankle support, time to peak ground reaction forces (GRF) was reduced, but had no influence on peak GRF and ankle joint moments during side-stepping and landing tasks $[25,28]$. Proprioception, measured using active movement extent discrimination apparatus (AMEDA), was improved with self-applied taping (0.022) and taping administered by a health professional (0.034) compared to no external ankle support, but neither was more efficacious than the other [43]. Currently, the NetballSmart and KNEE injury prevention programs do not endorse the use of external ankle support for the prevention of ankle injuries [26, 29].

\section{Footwear characteristics}

Early studies investigated the popularity and influence of shoe collar height in netball, with three collar heights (low-, mid-, and high-cut) commonly reported. One study found $60.0 \%$ of elite Jamaican netball athletes wore mid-cut footwear, less than half wore low-cut footwear (37.2\%) and very few wore high-cut footwear (2.7\%) [18]. In a second study, more than half (54.9\%) of state-netball athletes were wearing mid-cut footwear and $35.7 \%$ were wearing low-cut footwear when they sustained an ankle injury [24]. Given these studies were cross-sectional, however, it is unclear whether shoe collar height influences the risk of sustaining an ankle sprain in netball. A third study found no association between the age of netball shoes and lower limb injuries [46]. Biomechanical studies have reported that ankle kinematics, peak GRF, and ankle joint moments were not influenced by netball-specific footwear during side-stepping tasks [25]. However, netball-specific footwear has been reported to increase time to peak impact and reduced loading rates during running, cutting, and landing tasks, suggesting it may have the potential to reduce injuries in netball [32].

\section{Management of ankle sprains in netball}

Five studies presented data related to the management of ankle sprains and injuries in netball. Three subcategories were identified; these include treatment and rehabilitation (3 studies) and return to sport (3 studies). 


\section{Treatment and rehabilitation}

The literature suggests that a minority of netball athletes who sustain an ankle sprain or injury are referred to a health professional. Two studies reported extremely low referral rates $(14.1-27.1 \%)$ [21, 22], while another study reported higher referral rates to a physiotherapist (76.9\%) [20]. Composite treatment was most commonly undertaken by community-level netball athletes following an ankle injury (66.3-68.8\%) [21, 22]. Injury advice and home exercise programs were commonly provided (56.9-77.7\%). Ice and rest, in isolation or combination, were prescribed less often (0.0-31.4\%) [21, 22]. No study investigated the types of rehabilitation exercises undertaken by netball athletes following an ankle sprain or injury.

\section{Return to sport}

Early return to sport following ankle sprains and injuries were consistently reported across all studies in netball. During an international netball tournament, ankle sprains accounted for $17.4 \%$ of all injuries, with a quarter resulting in time-loss between 1-7 days (12.5\%) and 8-28 days (12.5\%) [38]. A second study reported three in four state-netball athletes returned to court immediately following an ankle sprain during a netball tournament [19]. Hopper et al. [20] reported $38.5 \%$ of community netball athletes returned to court for the following game during a 14-week season [20]. Of these, more than a third of netball athletes did not miss a netball match (38.5\%), $15.4 \%$ missed one match, $38.5 \%$ missed two matches and very few missed three or more games (7.7\%) [20]. No study reported whether netball athletes undertook to return to sport testing and/or received medical clearance before returning to netball (Table 1).

\section{Best-practice prevention of ankle sprains}

The following section describes the current best practice prevention for ankle sprains within the literature. These findings and prevention strategies undertaken by netball athletes described previously are then presented in Table 2.

\section{Injury prevention programs}

Injury prevention programs are a multi-modal combination of training strategies aiming to enhance strength, balance, landing, agility, and sport-specific tasks [47]. Single limb proprioceptive and neuromuscular exercises incorporating perturbation or sport-specific tasks have been shown to reduce ankle injuries by $30-45 \%$ [47] (Table 2). More recent netball studies have shown a $5-15 \%$ reduction in ankle injuries in New Zealand since the inception of the NetballSmart program [11]. Similar to NetballSmart and KNEE programs, other sporting codes across the world have implemented injury prevention programs including the Fédération Internationale de Football Association (FIFA) $11+$, FootyFirst, and Prep-to-Play programs [48-50]. The FIFA 11+has been shown to significantly reduce ankle sprain rates and severity of injury [51, 52]. Despite their effectiveness, low implementation rates of injury prevention programs within community sport remain a significant issue [53]. To address this, Australian Football has established implementation planning for FootyFirst to promote the adoption, resources, and effectiveness of injury prevention programs at the community level [54]. This may be of benefit for NetballSmart and KNEE programs at the community level to improve adoption and implementation rates. Overall, the evidence suggests injury prevention programs are highly effective in reducing ankle sprain rates in many sports. The early signs of the netballspecific program are promising, however, further data is required to determine their effectiveness and implementation at all competition levels (Table 2).

\section{External ankle support}

Evidence supports the use of external ankle support to effectively reduce ankle sprains $[47,55]$. In particular, taping and bracing were extremely effective in reducing secondary ankle sprains [56] (Table 2). Regarding primary prevention, low-quality studies and significant heterogeneity make it difficult to determine the effectiveness of external ankle support $[55,56]$. There is no clear indication of whether taping or bracing was more efficacious [56]. Bracing is often preferred over taping due to its simplicity, ease of application, and re-usable nature making it more practical and cost-effective [57]. In contrast, some athletes may prefer taping as it may provide greater comfort, support, compliance, and variability [58]. Despite it's effectiveness, netball athletes generally do not implement external ankle support until they have sustained an ankle sprain or developed instability $[10,23,24]$. Therefore, we recommend the use of taping or bracing to reduce the risk of ankle sprains during netball participation (Table 2). As both types of external ankle support are effective, netball athletes may preferentially choose between taping and bracing. There may also be some merit for netball-governing bodies to include external ankle support as a recommendation within their injury prevention programs to improve implementation rates $[26,29]$.

\section{Footwear}

There is currently no evidence that sport-specific footwear effectively reduces ankle sprain rates [59, 60]. A recent systematic review found very few studies have investigated footwear type and its effect on ankle sprains, 


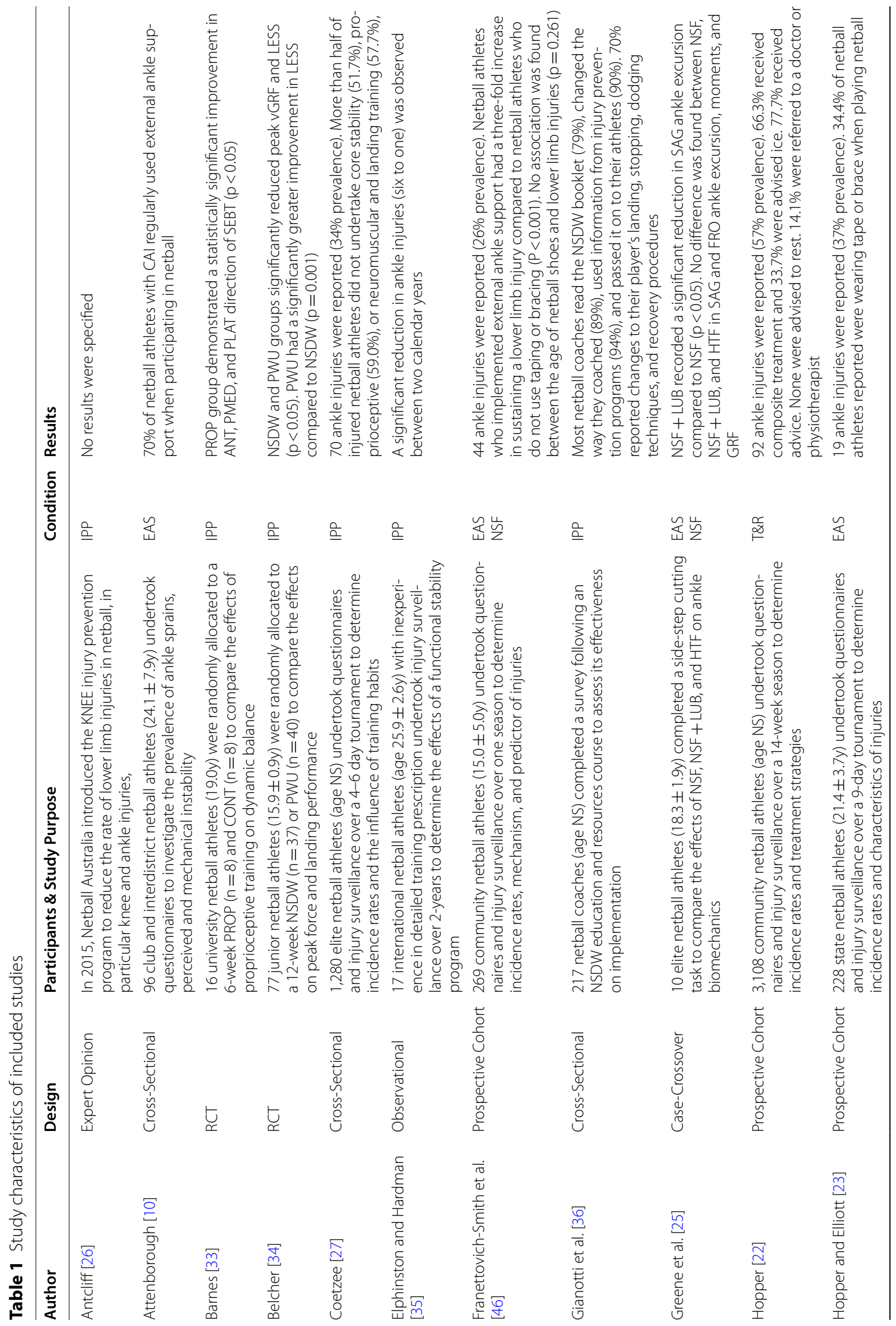




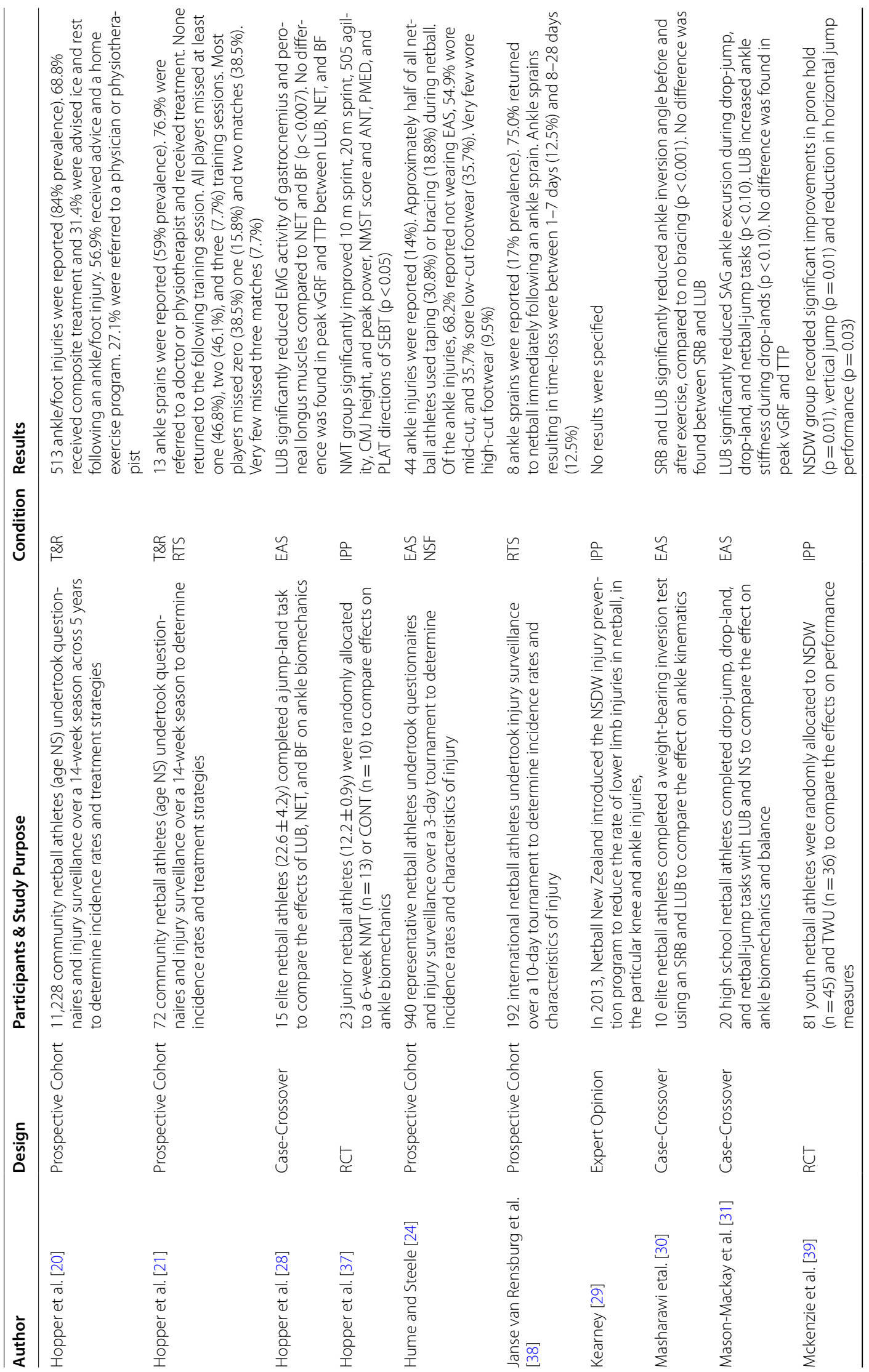




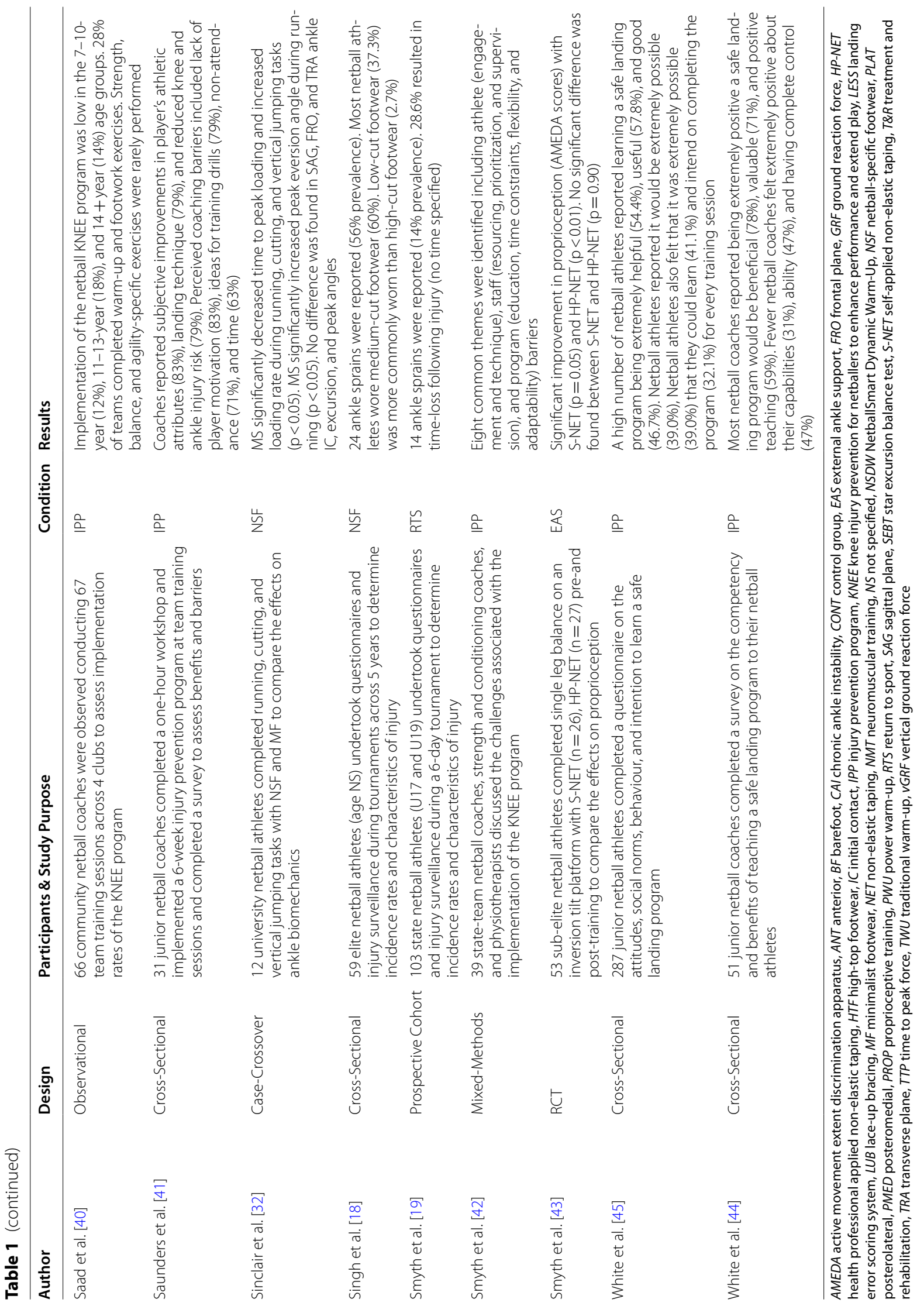


and the studies have shown no effect on reducing primary and secondary ankle sprains [56]. A prospective study also found shoe design did not influence the incidence of ankle sprains [61]. Due to inconclusive and limited evidence, we cannot conclusively recommend certain types of footwear in reducing the risk of ankle sprains. Further studies are necessary for determining whether footwear style, such as netball-specific footwear, may influence ankle biomechanics during netball-specific tasks that may predispose netball athletes to sustain an ankle sprain (Table 2).

\section{Best-practice management of ankle sprains}

The following section describes the current best practice management for ankle sprains within the literature. These findings and management strategies are undertaken by netball athletes described previously are then presented in Table 3.

\section{Treatment and rehabilitation}

Generally, there is a misconception that ankle sprains are "simple" injuries, which may result in poor rehabilitation and premature return to sport $[62,63]$. Similar to netball, research in other sports have shown many individuals do not seek medical advice and/or treatment from a health professional following an ankle sprain [64, 65]. A study by Hubbard-Turner [64] found two in three university students with CAI did not receive medical treatment following an ankle sprain, resulting in higher recurrent sprains, instability, and lower self-reported function. Using this evidence, poor medical-seeking behaviour and inadequate rehabilitation by netball athletes following an ankle sprain may contribute to high rates of recurrent ankle sprains and perceived instability previously reported in the literature [10, 14]. This emphasises the importance of good quality management following an ankle sprain to reduce the risk of developing CAI. In netball, insurance data shows a disproportionate number of ankle sprains and injuries receiving claims (29.3-31.0\%) [66, 67], compared to ankle injury rates (40\%) reported in epidemiological studies [7]. This may be due to a large number of ankle sprains or injuries that may not have been captured as some netball athletes may have continued participation, didn't seek medical treatment, were unsuccessful, or did not complete an insurance claim [66].The rehabilitation-oriented assessment (ROAST) was developed in 2018 by the International Ankle Consortium (IAC) and is considered one of the leading assessment tools for acute ankle sprains [68]. The ROAST is comprised of ten assessment measures to identify physical and psychological impairments presenting following an ankle sprain which can be addressed during rehabilitation (Table 3) [68]. In 2019, McKeon and Donovan [69] published a clinical commentary on the conservative management of ankle sprain using a perceptual-interdependence framework. Four best-practice recommendations were considered for the effective rehabilitation of ankle sprains, with the aim of re-establishing normal function, celltissue-body connection and sensory-motor function to the ankle-foot complex to reduce the negative sequelae associated with ankle sprains. We recommend clinicians incorporate the PAASS framework into their decisionmaking process when determining safe return to play for netball athletes following an ankle sprain (Table 3).

\section{Return to sport}

Until recently, there had been no consensus or criteria for a safe return to sport following an ankle sprain for any sport. Very few studies clearly define return to sport criteria following an ankle sprain, however, assessment of ankle range of motion, strength, neuromuscular control, balance, psychological readiness, and sport-specific tasks were common trends [70-72]. The lack of consensus demonstrates the current challenges clinicians face when determining the athlete's readiness to return to sport and may reflect the present attitudes and beliefs surrounding premature return to sport with ankle sprains. In netball, a large proportion of athletes return to sport almost immediately following an ankle sprain $[19,20,38]$. However, more research is required to determine if these athletes seek medical advice, undertake rehabilitation, and/or complete return to sport testing. In 2021, Smith et al. [73] undertook a Delphi study comprising of 155 health professionals to establish a consensus on assessment items determining appropriate return to sport following a lateral ankle sprain. The PAASS framework was developed comprising of five domains, including; pain severity, ankle impairments, athlete perception, sensorimotor control, and sport/functional performance [73]. The PAASS framework aims to improve assessment and decision-making for return to sport following a lateral ankle sprain [73]. We recommend clinicians incorporate the PAASS framework into their decision-making process when determining safe return to play for netball athletes following an ankle sprain (Table 3).

\section{Limitations and future research}

There is a need for more research examining the primary prevention and management of ankle sprains and injuries in netball athletes. In comparison to knee or ACL injuries, there are limited studies investigating the prevention and management of ankle sprains. Crucially, very few studies have investigated the management trends of ankle sprains in netball and the consequences of insufficient rehabilitation, leading to the development of CAI. With the recent implementation of injury prevention 
Table 3 Current management practices of ankle sprains in netball compared to best practice recommendations

\begin{tabular}{|c|c|c|}
\hline & Netball & best-practice recommendations \\
\hline \multirow[t]{2}{*}{$\begin{array}{l}\text { Treatment and reha- } \\
\text { bilitation }\end{array}$} & \multirow[t]{2}{*}{$\begin{array}{l}\text { The evidence suggests a minority of netball athletes } \\
\text { who sustain an ankle sprain or injury are referred to a } \\
\text { health professional. Composite treatment was most } \\
\text { commonly undertaken by community-level netball } \\
\text { athletes following an ankle injury. Injury advice and } \\
\text { home exercise programs were commonly provided. Ice } \\
\text { and rest, in isolation or combination, were prescribed } \\
\text { less often }\end{array}$} & $\begin{array}{l}\text { Rehabilitation-Oriented Assessment (ROAST) [68] } \\
\text { (1) Self-reported pain (NPS or FADI); (2) Ankle joint swelling (FEM); (3) } \\
\text { Ankle ROM (WBLT or A-SEBT); (4) Talocrural joint arthrokinematics } \\
\text { (PTGT); (5) Muscle strength (hand-held dynamometry); (6) Static pos- } \\
\text { tural balance (BESS or FLT); (7) Dynamic postural balance (SEBT); (8) } \\
\text { Gait (Visual Assessment); (9) Pre-injury physical activity level (Tegner } \\
\text { Scale); (10) Patient-reported outcome measures (FADI or FAAM) }\end{array}$ \\
\hline & & $\begin{array}{l}\text { Perceptual-Interdependence Framework [69] } \\
\text { NICE - NSAIDs, ice, compression, and elevation } \\
\text { EASY_external ankle support for at least } 12 \text { months following injury } \\
\text { Optimal Loading-early commencement of ankle-foot mobilisation } \\
\text { Exercise Rehabilitation—balance and coordination exercise program }\end{array}$ \\
\hline Return to sport & $\begin{array}{l}\text { Early return to sport following ankle sprains and injuries } \\
\text { were consistently reported across all studies in netball. } \\
\text { Up to three-in-four netball athletes returned to court } \\
\text { immediately following an ankle sprain. Time-loss fol- } \\
\text { lowing an ankle sprain varied across studies. All netball } \\
\text { athletes were able to return to court within } 4 \text { weeks } \\
\text { of their injury. Most were able to return within one or } \\
\text { two matches following their ankle sprain. No studies } \\
\text { reported whether netball athletes undertook to return } \\
\text { to sport testing and/or received medical clearance } \\
\text { before returning to netball }\end{array}$ & $\begin{array}{l}\text { PAASS Framework [73] } \\
\text { (P) Pain severity (during sports participation and over the last } 24 \text { h); } \\
\text { (A) Ankle impairments (ROM, strength, endurance and power); (A) } \\
\text { Athlete perception (perceived confidence/reassurance, stability \& } \\
\text { psychological readiness); (S) Sensorimotor control (proprioception \& } \\
\text { dynamic postural control/balance; (S) Sport/functional performance } \\
\text { (hopping, jumping, agility, sport-specific activities \& ability to com- } \\
\text { plete a full training session) }\end{array}$ \\
\hline
\end{tabular}

A-SEBT anterior reach of Star Excursion Balance Test, BESS Balance Error Scoring System, FAAM Foot and Ankle Ability Measure, FADI Foot and Ankle Disability Index, FEM figure of eight measurement, FIFA Fédération Internationale de Football Association, HHD hand-held dynamometry, NPS numerical pain scale, PTGT Posterior Talar Glide Test, ROM range of motion, SEBT star excursion balance test, WBLT weight-bearing lunge test

programs by netball governing bodies, further research should determine the effectiveness of these programs and their specific modalities in reducing ankle sprains. Additional research is also needed to determine the effects of netball-specific footwear, in isolation and in combination with external ankle support, on ankle sprains, instability, and lower limb injuries. Finally, the best-practice recommendations included within this review are generic guidelines within the literature, and not netball-specific, which may limit its translation from research to practice.

\section{Conclusion}

The findings of this scoping review suggest netball athletes do not implement current best-practice prevention and management strategies following an ankle sprain. Best-practice management includes a comprehensive rehabilitation and return to sport criteria following an ankle sprain, but the evidence shows netball athletes are not commonly referred to health professionals and almost immediately return to court. Netball-governing bodies currently endorse the use of injury prevention programs, but further studies are required to determine their effectiveness in preventing ankle sprains. Evidence suggests external ankle support influences ankle biomechanics and reduces the risk of ankle sprains, but netball athletes were only more likely to implement external ankle support after sustaining an ankle injury or developing CAI. Netball-specific footwear may be useful for reducing overuse injuries, however, there is a lack of evidence to suggest that specific footwear reduces the risk of ankle sprains. Current-best practice prevention and management of ankle sprains should be considered by clinicians, coaches, and athletes to reduce the prevalence and chronicity of ankle sprains in netball.

\section{Abbreviations}

CAl: Chronic ankle instability; IAC: International Ankle Consortium; EMG: Electromyography; ROAST: Rehabilitation-oriented assessment; ROM: Range of motion; RTS: Return to sport.

\section{Supplementary Information}

The online version contains supplementary material available at https://doi. org/10.1186/s13102-021-00342-9.

Additional file 1. PRISMA-SCR checklist.

Additional file 2. Search strategy.

\section{Acknowledgements}

Not applicable.

\section{Authors' contributions}

$P L R, K L P$, and ALB developed research question and structure of the scoping review. PLR and KLP undertook the literature search and data extraction. PLR completed the data analysis and drafted the manuscript. All authors revised and approved the final manuscript.

Funding

No funding was received. 


\section{Availability of data and materials}

All data generated or analysed during this study are included in this published article.

\section{Declarations}

\section{Ethics approval and consent to participate}

Not applicable.

\section{Consent for publication}

Not applicable.

\section{Competing interests}

The authors declare that they have no competing interests.

Received: 3 May 2021 Accepted: 11 September 2021

Published online: 18 September 2021

\section{References}

1. Australian Sports Commission. AusPlay Netball State of Play Report. 2019 https://www.clearinghouseforsport.gov.au/_data/assets/pdf_file/0003/ 821991/State_of_Play_Report___Netball.pdf. Accessed 09/02/2021.

2. Netball Australia. What Is Netball? 2020. https://netball.com.au/whatnetball. Accessed 09/02/2021.

3. Fox A, Spittle M, Otago L, Saunders N. Activity profiles of the Australian female netball team players during international competition: Implications for training practice. J Sport Sci. 2013:31(14):1588-95.

4. Brooks ER, Benson AC, Fox AS, Bruce LM. Physical movement demands of elite-level netball match-play as measured by an indoor positioning system. J Sport Sci. 2020:1-8.

5. International Netball Federation. Rules of Netball. 2020. https://netball. com.au/sites/default/files/2020-02/INF-RulesofNetball2020.pdf. Accessed 07/05/2020.

6. Williams $\mathrm{R}, \mathrm{O}^{\prime}$ Donoghue $\mathrm{P}$. Lower limb injury risk in netball: a time-motion analysis investigation. J Hum Mov Stud. 2005;49(5):315-31.

7. Fong DT-P, Hong Y, Chan L-K, Yung PS-H, Chan K-M. A systematic review on ankle injury and ankle sprain in sports. Sports Med. 2007:37(1):73-94.

8. Downs C, Snodgrass SJ, Weerasekara I, Valkenborghs SR, Callister R. Injuries in netball-a systematic review. Sports Med Open. 2021;7(1).

9. Pillay T, Frantz JM. Injury prevalence of netball players in South Africa: the need for in jury prevention. S Afr J Physiother. 2012;68(3).

10. Attenborough AS, Sinclair PJ, Sharp T, Greene A, Stuelcken M, Smith RM, et al. A snapshot of chronic ankle instability in a cohort of netball players. J Sci Med Sport. 2016;19(5):379-83.

11. Belcher S, Whatman C, Brughelli M, Borotkanics R. Ten-year nationwide review of netball ankle and knee injuries in New Zealand. J Sci Med Sport. 2020;23(10):937-42

12. Gribble PA, Delahunt E, Bleakley C, Caulfield B, Docherty C, Fourchet $F$, et al. Selection criteria for patients with chronic ankle instability in controlled research: a position statement of the international ankle consortium. J Orthop Sports Phys Ther. 2013:43(8):585-91.

13. Hertel J, Corbett RO. An updated model of chronic ankle instability. J Athl Train. 2019:54(6):572-88

14. Langeveld E, Coetzee FF, Holtzhausen LJ. Epidemiology of injuries in elite South African netball players. S Afr J Res Sport Phys Education Recreat. 2012;34(2):83-93.

15. McGrath AC, Ozanne-Smith J. Attacking the goal of netball injury prevention: a review of the literature. Monash University Accident Research Centre; 1998

16. Whitehead S, Weakley J, Cormack S, Alfano H, Kerss J, Mooney M et al. The applied sports science and medicine of netball: a systematic scoping review. Sports Med. 2021.

17. Tricco AC, Lillie E, Zarin W, O'Brien KK, Colquhoun H, Levac D, et al. PRISMA extension for scoping reviews (PRISMA-SCR): checklist and explanation. Ann Intern Med. 2018;169(7):467-73.

18. Singh P, Mansingh A, Palmer W, Williams EW. Injuries in elite Jamaican netballers. West Indian Med J. 2013;62(2):118-21.
19. Smyth EA, Piromalli L, Antcliff A, Newman P, Waddington G, Weissensteiner JR, et al. A prospective study of health problems at the $201817 / \mathrm{U}$ and 19/U Australian National Netball Championships with comparison of surveillance methodology. J Sci Med Sport. 2020;23(3):215-21.

20. Hopper DM, Hopper JL, Elliott BC. Do selected kinanthropometric and performance variables predict injuries in female netball players? J Sport Sci. 1995;13(3):213-22.

21. Hopper D, Elliott B, Lalor J. A descriptive epidemiology of netball injuries during competition: a five year study. Br J Sports Med. 1995;29(4):223-8.

22. Hopper D. A survey of netball injuries and conditions related to these injuries. Aust J Physiother. 1986;32(4):231-9.

23. Hopper D, Elliott B. Lower limb and back injury patterns of elite netball players. Sports Med. 1993;16(2):148-62.

24. Hume PA, Steele JR. A preliminary investigation of injury prevention strategies in netball: Are players heeding the advice? J Sci Med Sport 2000;3(4):406-13.

25. Greene AJ, Stuelcken MC, Smith RM, Vanwanseele B. The effect of external ankle support on the kinematics and kinetics of the lower limb during a side step cutting task in netballers. BMC Sports Med Rehabilit. 2014;6(1):42.

26. Antcliff A. Netball Australia invited - KNEE program. J Sci Med Sport. 2017;20:e6-7.

27. Coetzee D, Langeveld E, Holtzhausen L. Training habits, training surface and injuries among South African netball players. S Afr J Res Sport Phys Education Recreat. 2014:36(3):39-49.

28. Hopper DM, McNair P, Elliott BC. Landing in netball: effects of taping and bracing the ankle. Br J Sports Med. 1999:33(6):409-13.

29. Kearney S. NetballSmart-Netball New Zealand Injury Prevention Programme. Engage and make a difference. J Sci Med Sport. 2019:22:S90.

30. Masharawi Y, Carmeli E, Masharawi R, Trott P. The effect of braces on restricting weight-bearing ankle inversion in elite netballers. Phys Ther Sport. 2003;4(1):24-33.

31. Mason-Mackay AR, Whatman C, Reid D, Lorimer A. The effect of ankle bracing on landing biomechanics in female netballers. Phys Ther Sport. 2016;20:13-8.

32. Sinclair J, Chockalingam N, Naemi R, Vincent $H$. The effects of sportspecific and minimalist footwear on the kinetics and kinematics of three netball-specific movements. Footwear Sci. 2015;7(1):31-6.

33. Barnes RY, Wilson M, Raubenheimer J. Effect of a core stability, M. gluteus medius and proprioceptive exercise programme on dynamic postural control in netball players. S Afr J Res Sport Phys Education Recreat. 2020:42(1):1-11.

34. Belcher S, Whatman C, Brughelli M, Borotkanics R. Short and long versions of a 12-week netball specific neuromuscular warm-up improves landing technique in youth netballers. Phys Ther Sport. 2021;49:31-6.

35. Elphinston J, Hardman SL. Effect of an integrated functional stability program on injury rates in an international netball squad. J Sci Med Sport. 2006;9(1-2):169-76.

36. Gianotti S, Hume PA, Tunstall H. Efficacy of injury prevention related coach education within netball and soccer. J Sci Med Sport. 2010;13(1):32-5.

37. Hopper A, Haff EE, Barley OR, Joyce C, Lloyd RS, Haff GG. Neuromuscular training improves movement competency and physical performance measures in 11-13-year-old female netball athletes. J Strength Cond Res. 2017:31(5):1165-76

38. Janse van Rensburg DC, Bryant G, Kearney S, Singh P, Devos A, Jansen van Rensburg A et al. The epidemiology of injury and illness at the Vitality Netball World Cup 2019: an observational study. Phys. Sports Med. 2021:1-10.

39. McKenzie CR, Whatman C, Brughelli M, Borotkanics R. The effect of the NetballSmart Dynamic Warm-up on physical performance in youth netball players. Phys Ther Sport. 2019:37:91-8.

40. Saad T, Davies L, Smith M. Implementation of an injury prevention programme in community netball: An observational study. J Sport Sci. 2021:1-9.

41. Saunders N, Otago L, Romiti M, Donaldson A, White P, Finch C. Coaches' perspectives on implementing an evidence-informed injury prevention programme in junior community netball. Br J Sports Med. 2010:44(15):1128-32 
42. Smyth E, Appaneal R, Drew M, Antcliff A, Waddington G, Newman P et al. Identifying the challenges to implementing a neuromuscular warm-up in pre-elite netball. Int J Sports Sci Coach. 2021:174795412199846.

43. Smyth E, Waddington G, Witchalls J, Newman P, Weissensteiner J, Hughes $S$, et al. Does ankle tape improve proprioception acuity immediately after application and following a netball session? A randomised controlled trial. Phys Ther Sport. 2021:48:20-5.

44. White PE, Otago L, Saunders N, Romiti M, Donaldson A, Ullah S, et al. Ensuring implementation success: how should coach injury prevention education be improved if we want coaches to deliver safety programmes during training sessions? Br J Sports Med. 2014;48(5):402-3.

45. White PE, Ullah S, Donaldson A, Otago L, Saunders N, Romiti M, et al. Encouraging junior community netball players to learn correct safe landing technique. J Sci Med Sport. 2012;15(1):19-24.

46. Franettovich-Smith MM, Mendis MD, Parker A, Grantham B, Stewart S, Hides J. Injury surveillance of an Australian community netball club. Phys Ther Sport. 2020;44:41-6.

47. Kaminski TW, Needle AR, Delahunt E. Prevention of Lateral Ankle Sprains. J Athl Train. 2019;54(6):650-61.

48. FIFA Medical Network. FIFA 11+. 2020. https://www.fifamedicalnetwork. com/lessons/prevention-fifa-11/. Accessed 07/02/2021.

49. AFL Community. FootyFirst. 2020. http://www.aflcommunityclub.com.au/ index.php?id=906. Accessed 09/02/2021.

50. Coach AFL. Prep-To-Play Skills. 2020. https://coach.afl/prep-play-skills. Accessed 10/02/2021.

51. Jain N, Kemp S, Hayward P, Murray DJ. Frequency of foot and ankle injuries in professional footballers following the introduction of Prehab which incorporates elements of the FIFA 11+. Arthroscopy. 2012:40-.

52. Mayo M, Seijas R, Álvarez P. Structured neuromuscular warm-up for injuryprevention in young elite football players. Rev Esp Cir Ortop Traumatol. 2014;58(6):336-42.

53. Fortington LV, Donaldson A, Lathlean T, Young WB, Gabbe BJ, Lloyd D, et al. When 'just doing it' is not enough: Assessing the fidelity of player performance of an injury prevention exercise program. J Sci Med Sport. 2015;18(3):272-7.

54. Donaldson A, Lloyd DG, Gabbe BJ, Cook J, Finch CF. We have the programme, what next? Planning the implementation of an injury prevention programme. Inj Prev. 2017;23(4):273-80.

55. Barelds I, Van Den Broek AG, Huisstede BMA. Ankle Bracing is Effective for Primary and Secondary Prevention of Acute Ankle Injuries in Athletes: A Systematic Review and Meta-Analyses. Sports Med. 2018;48(12):2775-84.

56. Doherty C, Bleakley C, Delahunt E, Holden S. Treatment and prevention of acute and recurrent ankle sprain: an overview of systematic reviews with meta-analysis. Br J Sports Med. 2017;51(2):113-25.

57. Verhagen EALM, Bay K. Optimising ankle sprain prevention: a critical review and practical appraisal of the literature. $\mathrm{Br} J$ Sports Med. 2010;44(15):1082-8.

58. Wilkerson GB. Biomechanical and Neuromuscular Effects of Ankle Taping and Bracing. J Athl Train. 2002;37(4):436-45.

59. Barrett J, Bilisko T. The Role of Shoes in the Prevention of Ankle Sprains. Sports Med. 1995:20(4):277-80.
60. Verhagen EA, van Mechelen W, de Vente W. The effect of preventive measures on the incidence of ankle sprains. Clin J Sport Med. 2000:10(4):291-6.

61. Curtis CK, Laudner KG, McLoda TA, McCaw ST. The role of shoe design in ankle sprain rates among collegiate basketball players. J Athl Train. 2008;43(3):230-3

62. Medina Mckeon JM, Bush HM, Reed A, Whittington A, Uhl TL, McKeon PO. Return-to-play probabilities following new versus recurrent ankle sprains in high school athletes. J Sci Med Sport. 2014;17(1):23-8.

63. Miklovic TM, Donovan L, Protzuk OA, Kang MS, Feger MA. Acute lateral ankle sprain to chronic ankle instability: a pathway of dysfunction. Physician Sports Med. 2018:46(1):116-22.

64. Hubbard-Turner T. Lack of Medical Treatment From a Medical Professional After an Ankle Sprain. J Athl Train. 2019;54(6):671-5.

65. Hiller CE, Nightingale EJ, Raymond J, Kilbreath SL, Burns J, Black DA, et al. Prevalence and impact of chronic musculoskeletal ankle disorders in the community. Arch Phys Med Rehabil. 2012;93(10):1801-7.

66. Joseph C, Naughton G, Antcliff A. Australian netball injuries in 2016: An overview of insurance data. J Sci Med Sport. 2019;22(12):1304-8.

67. Otago $L$, Peake J. The role of insurance data in setting priorities for netball injury prevention strategies. J Sci Med Sport. 2007;10(2):105-9.

68. Delahunt E, Bleakley CM, Bossard DS, Caulfield BM, Docherty CL, Doherty C, et al. Clinical assessment of acute lateral ankle sprain injuries (ROAST): 2019 consensus statement and recommendations of the International Ankle Consortium. Br J Sports Med. 2018:52(20):1304-10.

69. McKeon PO, Donovan L. A Perceptual Framework for Conservative Treatment and Rehabilitation of Ankle Sprains: An Evidence-Based Paradigm Shift. J Athl Train. 2019;54(6):628-38.

70. Kaminski TW, Hertel J, Amendola N, Docherty CL, Dolan MG, Hopkins JT, et al. National Athletic Trainers' Association Position Statement: Conservative Management and Prevention of Ankle Sprains in Athletes. J Athl Train. 2013:48(4):528-45.

71. Wikstrom EA, Mueller C, Cain MS. Lack of Consensus on Return-to-Sport Criteria Following Lateral Ankle Sprain: A Systematic Review of Expert Opinions. J Sport Rehabilit. 2020;29(2):231-7.

72. Tassignon B, Verschueren J, Delahunt E, Smith M, Vicenzino B, Verhagen E, et al. Criteria-Based Return to Sport Decision-Making Following Lateral Ankle Sprain Injury: a Systematic Review and Narrative Synthesis. Sports Med. 2019;49(4):601-19.

73. Smith MD, Vicenzino B, Bahr R, Bandholm T, Cooke R, Mendonça LDM et al. Return to sport decisions after an acute lateral ankle sprain injury: introducing the PAASS framework - an international multidisciplinary consensus. Br J Sports Med. 2021:bjsports-2021-1.

\section{Publisher's Note}

Springer Nature remains neutral with regard to jurisdictional claims in published maps and institutional affiliations.
Ready to submit your research? Choose BMC and benefit from:

- fast, convenient online submission

- thorough peer review by experienced researchers in your field

- rapid publication on acceptance

- support for research data, including large and complex data types

- gold Open Access which fosters wider collaboration and increased citations

- maximum visibility for your research: over 100M website views per year

At $\mathrm{BMC}$, research is always in progress.

Learn more biomedcentral.com/submissions 